\title{
Assistive Technology for Autistic Children: A Review
}

\author{
Divya Martolia* and Ritu Gupta
}

\author{
Dept of Family Resource Management, College of Community Science, Punjab Agricultural \\ University, Ludhiana-141004, Punjab, India \\ *Corresponding author
}

\section{Keywords \\ Assistive technology, Autism, Rehabilitation, \\ Social \\ communication Skill and Behaviour}

Article Info

Accepted:

20 June 2020

Available Online:

10 July 2020

\section{A B S T R A C T}

Autism spectrum disorder (ASD) is a condition related to mental development disability that impacts how a person perceives and socializes with others, causing problems in behaviour, social interaction and communication. The disorder also includes limited and repetitive patterns of behaviour. Moreover, autism has broad variation in the type and severity of disorder children experience and this disorder can occurs in any strata of society, therefore it is known as "spectrum disorder". Despite that ASD has long time effect, however, proper medical treatment can aid to better recovery and functioning of the children to interact within their social circle. Consequently, assistive technology has been a core link in the chain that enables children with disabilities to lead a life where they enjoy and exercise their rights rather than being destitute. This review paper focuses on investigating the various technologies and its' effect on special need children to improve their performance in education and assist in their rehabilitation. This paper expound about the assistive technology and its relation with autism disorder. The study is supported by literature reviewed through various sources such as Google scholar, Springer, Pub Med and books. In conclusion, assistive technologies work as imperative tool which seriously boost autistic children confidence in independently functioning skill. Indeed, it also improves the communication skill and promotes interaction, cognitive process and social development. The framework of the study identifies the significance of technology, which enhance the constructive skill of the autistic children. Furthermore, it highlights the approach to emerging assistive device which initiate a better quality of life for the autistic children.

\section{Introduction}

According to the Indian Scale Assessment of Autism, approximately 2 million children with autism are from India (Chauhan, 2019). Autism spectrum disorder (ASD) is a neurological development disorder that affects social communication, social interaction, restricted and repetitive patterns in behaviours and activities (American
Psychiatric Association 2013).Autism is simply mental retardation, where people lack in interest with other people in a group of society. The exact cause of autism is still not known, but researches indicate that it may be caused due to the combination of genetic and environmental factors. The symptoms of autism in children appear during infancy stage. 
Moreover, autism has broad variation in the type and severity of disorder children experience, therefore, it is also known as "spectrum disorder". As there are three types of autism spectrum disorders identified: Autistic Disorder (which is also called "classic" autism), Asperger Syndrome and Pervasive Developmental Disorder. Autistic children are treated as social stigma in the society and this make it difficult for the children to survive where everyone is staring them and jugging them for being the part of this judgemental society. These days, the children diagnosed with autism disorder have grown at alarming rate.

Consequently, narrow focus, language issues, lack of attention etc. hinders children growth, following this, family also suffer because they have to observe their child for 24 hours seeing as he/she totally depends on their caretaker. According to the Technology-Related Assistance for Individuals with Disabilities Act of 1988 (Public Law 100-407), an assistive technology refers to any item, piece of equipment, or product system, whether acquired commercially, off-the-shelf, modified or customized, that is used to increase, maintain, or improve functional capabilities of individuals with disabilities.

For example wheelchairs, eyeglasses, hearing aids, Braille printers, augmentative communication systems, text-to-speech software, voice recognition software etc. An Assistive technology service is any service that directly assists an individual with a disability in the selection, acquisition, or use of an assistive technology device. An assistive technology serves two major purposes: to augment an individual's strengths, thereby counter balancing the effects of the disability, and to provide an alternative mood of performing a task. Thus, the use of technology allows students to compensate for their disability or circumvent it entirely (Lewis, 1998).

According to Konstantinidis et al., (2009) the ICT (Information Communication and Technology) sector over the last few years, have created excellent applications and platforms for the special need children suffering from autism disorder to match their pace with other fellow mates in learning process. The use of technology and its advance version is undoubtedly providing better environment for stable learning. The importance of ICTs in education calls upon educationists to identify the challenges of ICTs integration into teaching and learning.

The purpose is to improve the teaching and learning quality for children with learning disabilities such as autism (Mandina, 2015). So, the idea behind this paper is to highlight the assistive technologies used by autistic children and its effect in their day to day life.

The specific objectives of the study are to review the assistive technology used for the children suffering from autism. And also to study the impact of assistive technology in their day to day life.

\section{A review: Assistive technology for autistic children}

Diamond et al (2003) in their study analyzed that tele-rehabilitation service is an emerging method used to deliver rehabilitation services to the children with autism. It creates least restrictive environment for them to learn and interact with others and reduces the time and costs of offering rehabilitation services. It is considered as a partial replacement of face-toface physical rehabilitation. Nowadays, computer aided technology have imperative role to operate the rehabilitation services. 
Table.1 Areas indicating autism symptoms

\begin{tabular}{|c|l|l|}
\hline Sr. No. & \multicolumn{1}{|c|}{ Areas } & \multicolumn{1}{c|}{ Indicators } \\
\hline $\mathbf{1 .}$ & Social Interaction In Autism & $\begin{array}{l}\text { Lack of peers interaction } \\
\text { Hard to correlate to their peers and other people's actions } \\
\text { Avoid eye contact } \\
\text { Struggles to carry on conversation with people }\end{array}$ \\
\hline $\mathbf{2 .}$ & Communication In Autism & $\begin{array}{l}\text { Unresponsive to verbal prompts } \\
\text { Use modulation in their voice while speaking } \\
\text { Hard to understand non-verbal communication } \\
\text { Struggles with imaginative thought process }\end{array}$ \\
\hline 3. & Restricted behaviour & $\begin{array}{l}\text { Show hyper or hypo behaviour to external stimulus } \\
\text { Repetitive behaviour, like throwing items or saying one } \\
\text { word again and again } \\
\text { Mood swing due to disruption } \\
\text { Talking excessively and endlessly about a particular } \\
\text { interest, often not allowing anyone else to speak }\end{array}$ \\
\hline
\end{tabular}

Source: Anonymous (2019)

La'nyiand Tilinger (2004) stated that the platform of edutainment where addition of entertainment props in education content such as photographs or sketches of items used in daily life displayed on the screen of the desktop for people with autism. Indeed, the use of computer aid technology help the autistic to make out the difference on the basis of the respective item size, color, type etc. Furthermore, the interactive technology using animated graphs provides a better understanding and motivates them to associate the items with sounds and words. Likewise, the technology seems as boon for the autistic children to construct their social cognitive skills.

Assistive technology as boon for individuals with disabilities, that aids to functional benefit and make their task possible. The advance tech-therapy paved way for children with autism for stable learning environment as to survive in the social circle. Consequently, the experts state the use of various methods for autistic children to improve their social communication skills. Also, it has been founded in the study of Collet-Klingenberg
(2008) that augmentative and alternative communication known as best method recommended to overcome the problems related to social communication skill among autistic children. The mode of picture exchange communication system used to help the learner with autism have stable learning environment to understand and correlate the pictures with their functioning.

Jowett et al., (2012)evaluated the video modeling package and its effect on five year old boy with autism disorder. The technology used iPad- based video modeling to teach the child basic numeracy skills. The outcome of the study showed that there was positive effect on the child ability to identify and write 1- 7 Arabic numerals. Further, the study showed an affirmative effect of video modeling package for teaching children with autism disorder. The video modeling technology undoubtedly, assists the autistic children with constant learning environment and helps them to stay motivated as well as increase their attention power.

Murdock et al., (2013) conducted the study on 
use of an i-Pad to increase play dialogue of pre-schoolers with autism spectrum disorder in four pre-school children with autism disorder. The participants were showed video clips which depict pictures subsequently producing scripted character dialogue. The result revealed that three participants showed increase in play dialogue behaviour, which give a picture of the power of technology and its benefit to the special need to cope up with the lack of social cognitive behaviour.

Shrikumar (2015) in his article written to The Hindu newspaper elucidated about how technology helps the autistic children to cope up with lack of social interaction and restricted behaviour in social circle. Moreover, technology is about concrete visual along with voice such as AWAAZ OR BOL, some of the applications used for language development skill with audio and visual component, picture exchange communication method. These are friendly applications which boost confidence, enhance constructive language skill development and social interaction in their peer group.

Renju and Megha (2016) in their study revealed that children with autism are always isolated and treated as destitute because of their lack in social communication and restricted behaviour. Although birth of technology has been benefited to all the humankind but it has been more special for those group of people who are not as other individuals in the society. Autism is a neurological disorder, a person with autism faces various problems in their day to day activity. Consequently, Computer aided technology enables them to improve their social, cognitive skill and stabilize their learning environment, this shows the impact of technology motivating the children with autism.

Hedges et al., (2018) in their study examined the use of technology in supportive ways by secondary students with autism. Around 472 adolescents with autism spectrum disorder of high school were surveyed. Consequently, it has been found that use of technological setup at home and school environment help the student to cope up with the obstacles they are facing in their day to day activity. Further, the technology aid in reduction in anxiety, enhance independent functional skills and engage them with other social skills.

\section{Assistive tool for autistic children}

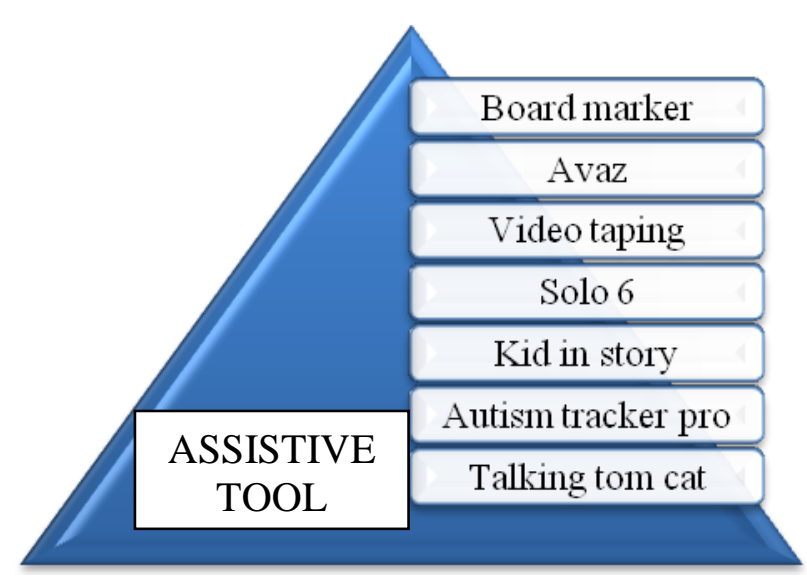

Source: Renju and Megha (2016) 
In conclusion the autistic children are special one with neurological disorder different from normal individuals. They need extra care and attention from their loved ones. In addition, the technology has been a core link in the chain that enables children with autism to enjoy their life rather than being destitute. Using ICT (Information Communication and Technology) in effective way for therapy and education of children with autism has been proved a better approach for treatment. Many researches have stated that autistic children showed sign of improvement in communication skill through mode of illustration as they lack verbal skills and the technology is set as boon for these special group whom society seek as burden.

With respect to analysis of review of literature related to technology for autistic children it has been found that supportive technology setup at school and home environment helped a lot to the autistic children to work out on their weak phase. Indeed, poor coordination of neurological development has resulted in a shortfall in social interaction and overall cognitive development in autistic children. Undoubtedly, assistive technology provided an enhanced edutainment platform for autistic children to upgrade their social skill, behavioural skill, constructive skill for better learning and for healthier life. There are some friendly technologies such as BOL, AWAAZ, VIDEOTAPING, BOARD MARKER and many other smart interactive applications. Certainly these applications assist children to engage them with this kind of learning platform to cope up with lack of functioning and social skill.

\section{References}

American Psychiatric Association. 2013. Diagnostic and Statistical Manual of Mental Disorders, 5th Edition: DSM-5. Washington, DC: Publisher.
Anonymous. 2019. Signs and Symptoms of Autism Spectrum Disorders, National Center on Birth Defects and Developmental Disabilities, Centers for Disease Control and Prevention.. Retrieved from $w w w . c d c . g o v>$ ncbddd > autism $>$ signs.

Chauhan, A., J. K. Sahu, N. Jaiswal, K. Kumar, A. Agarwal, J. Kaur, S. Singh and M. Singh. 2019. Prevalence of autism spectrum disorder in Indian children: a systematic review and metaanalysis, Neurol India, 67(1) : 100-104.

Collet-Klingenberg, L. (2008). Overview of Picture Exchange Communication System (PECS) for children and youth with autism spectrum disorders. Madison, WI: National Professional Development Institute on ASD, The Waisman Center, The University of Wisconsin.

Diamond, B., G. Shreve and J. Bonilla. 2003. Tele-rehabilitation, cognition and useraccessibility, Neuro Rehabilitation, 18(2):171-177.

Hedges, S. H., S.L. Odom, K. Hume and A. Sam.2018. Technology use as a support tool by secondary students with autism, Autism, 22(1): 70-79.

Jowett, E.L., D.W. Moore and A. Anderson.2012. Using an iPad-based video modelling package to teach numeracy skills to a child with an autism spectrum disorder, Dev. Neurorehabilitation, 15 (4):304-312.

Konstantinidis, E., A. Luneski, C. Frantzidis, C. Pappas and P. Bamidis.2009. A proposed framework of an interactive semi-virtual environment for enhanced education of children with autism spectrum disorders, The 22nd IEEE International Symposium on ComputerBased Medical Systems (CBMS).

La'nyi, C. S. and A. Tilinger.2004. Multimedia and virtual reality in the rehabilitation of autistic children, 
Springer-Verlag Berlin Heidelberg, 3118: 22-28.

Lewis, L. B. 1998. Assistive technology and learning disabilities: today's realities and tomorrow's promises, J Learning Disabilities, 31(1):16-26.

Mandina, S. 2015. Integrating ICTs into the environmental science primary school classroom in Chegulu district, Zimbabwe: problems and solutions, European J Sci. Mathematics Education, 3(1): 90-96.

Murdock, L., J. Ganz, and J. Crittendon. 2013. Use of an ipad play story to increase play dialogue of preschoolers with autism spectrum disorders, J Autism Dev. Disorder, 9:2174-2189.

Renju, K. and C. Megha. 2016. Technology and autism: is technology a boon for autistic children? int $\mathrm{j}$ computer sci trends tech., 4(3): 343-345.

Shrikumar, A. 2015.Technology helps in autism, The Hindu. Retrieved from https://www.thehindu.com/features/met roplus/technology-helps-inautism/article7057808.ece, www.govinfo.gov>content $>$ pkg $>$ STAT UE 102: Public Law 100-407.

\section{How to cite this article:}

Divya Martolia and Ritu Gupta. 2020. Assistive Technology for Autistic Children: A Review. Int.J.Curr.Microbiol.App.Sci. 9(07): 2170-2175. doi: https://doi.org/10.20546/ijcmas.2020.907.253 